\title{
REDES E ICEBERGS: DIAGRAMAS DE PODER EM DISPUTA
}

\section{Henrique Z.M. Parra}

\section{RESUMO}

O artigo tem dois objetivos. Primeiramente, busca exercitar uma forma de conhecimento poéticocientífico na medida em que se deixa guiar pela apreensão imaginativa dos problemas empíricos analisados através de uma pesquisa visual e da produção de expressões imagéticas que abram outras vias de reflexão sobre os casos investigados. Em segundo lugar, o artigo analisará dois eventos relativos à internet que tiveram grande repercussão na imprensa brasileira em julho de 2008, procurando evidenciar uma disputa entre configurações distintas do poder que se desenvolvem sob a superfície da internet.

\section{PALAVRAS-CHAVES}

Imagem; Internet; Conhecimento; Comunicação; Tecnologia; Poder

\section{NETS AND ICEBERGS: DIAGRAMS OF POWER IN DISPUTE}

\begin{abstract}
This paper has two objectives. First, it aims to put into practice a form of poetic-scientific knowledge to the extent that we are guided by an imaginative comprehension of the empirical problems analyzed; the paper promotes this practice through visual research and through the production of image-based expression, which provide alternative means to reflect on the cases analyzed. Second, the paper analyzes two events related to the internet that strongly impacted Brazilian media in July 2008; the analysis of these two cases focuses on distinct power dynamics that developed underneath the front end of the internet.
\end{abstract}

\section{KEYWORDS}

Internet; Knowledge; Communication; Technology; Power, Image 
Ao ler o jornal Folha de S.Paulo deste dia deparei-me com uma página dupla no meio do primeiro caderno que trata principalmente de assuntos de interesse nacional. A página da esquerda (A16) estava toda ocupada por uma única reportagem e a página da direita (A17) continha um informe publicitário de página inteira, intitulado “Comunicado à População do Estado de São Paulo”.

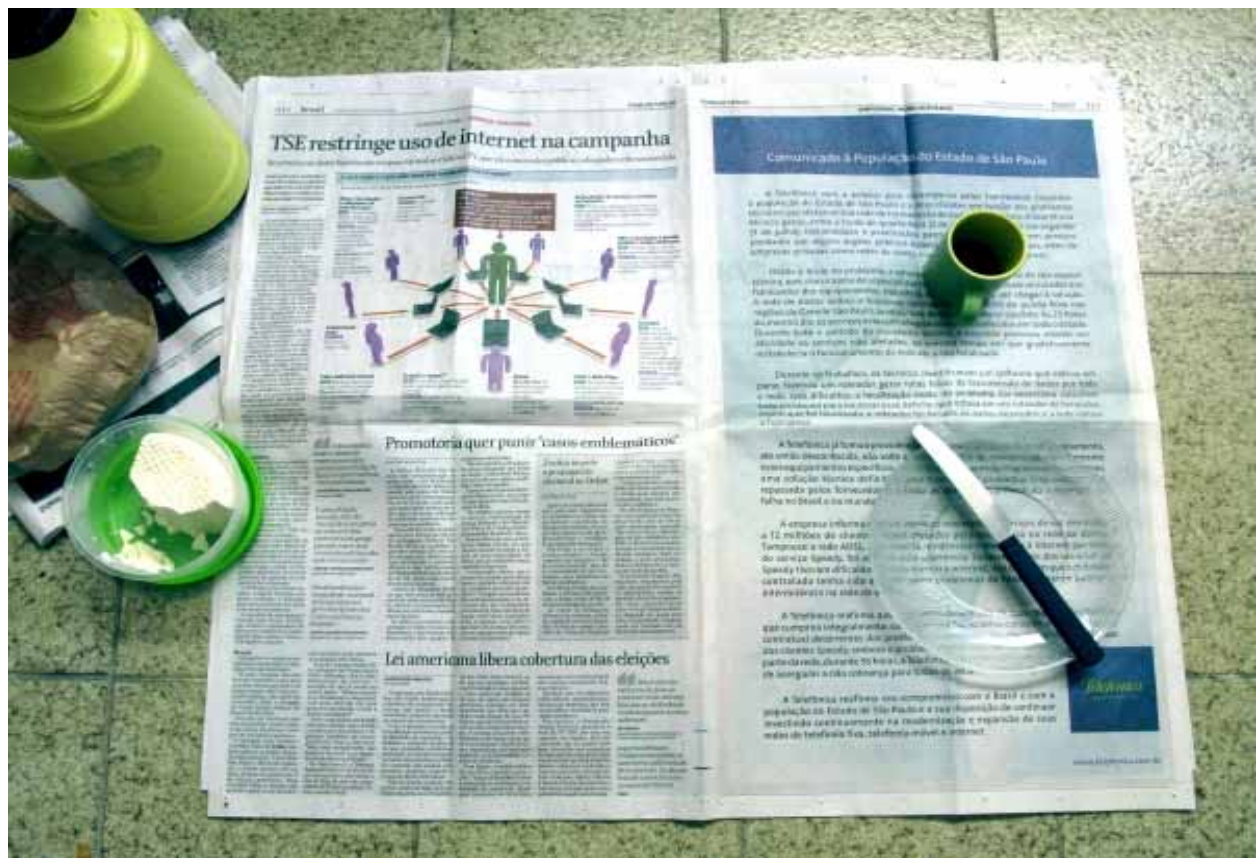

Figura 1 - Fotografia do Jornal Folha de S.Paulo, dia 06 de julho de 2008, páginas A16 e A17.

Na primeira semana deste mês, dois assuntos relacionados à internet no Brasil tiveram ampla repercussão na imprensa. No entanto, qualquer conexão entre eles pode ter passado desapercebida. Refiro-me aqui a: (1) a Resolução $n^{\circ} 22.718$ do Tribunal Superior Eleitoral $^{1}$ (publicada em 28 de fevereiro de 2008), regulando o uso da internet na disputa eleitoral de 2008, a partir de julho deste ano; (2) o “apagão da internet”, falha técnica da Telefônica na prestação de serviço de comunicação à rede, que deixou inúmeros serviços públicos do estado de São Paulo inoperantes, bem como diversas empresas privadas e indivíduos sem acesso ao ciberespaço. Ambos os eventos estavam reunidos naquela página central do jornal. O primeiro, a reportagem sobre a decisão do TSE, ocupando a página da esquerda e o segundo, sobre o “apagão” da internet da Telefônica, inserido na página da direita (cf. Figura 1). 
Seria coincidência a disposição gráfica desses dois assuntos? Ou talvez, simplesmente, a reportagem relacionada à regulação da internet tenha atraído a atenção dos publicitários da empresa Telefônica, sugerindo que um espaço visualmente "equivalente” interessaria, por proximidade temática, ao mesmo público da matéria ao lado, no caso os “internautas”? De fato, apenas o diagramador ou o setor comercial do jornal poderiam responder a essas perguntas.

Podemos, no entanto, avançar mesmo desconhecendo a motivação original. Para todos os efeitos, o que nos interessa aqui é tomar esta "coincidência” visual como algo bom para se pensar. Afinal, a simples interrogação ou o exercício imaginativo sobre as homologias $^{2}$ entre dois assuntos, aparentemente díspares, podem servir de agente mobilizador para nossa investigação. Partimos de uma simples pergunta: o que há de comum entre os dois acontecimentos? A maneira que escolhemos para responder a esta indagação, dentre várias alternativas, virá na forma de uma imagem. Ou melhor, virá das problematizações provocadas por esta e outras imagem.

\footnotetext{
${ }^{1}$ A Resolução n 22.718 está disponível no link: http://www.tse.gov.br/downloads/eleicoes2008/r22718.pdf ${ }^{2} \mathrm{Na}$ homologia, diferentemente da analogia, as relações de correspondência são estabelecidas a partir de elementos diferentes. A ligação dá-se através da interpretação.
} 


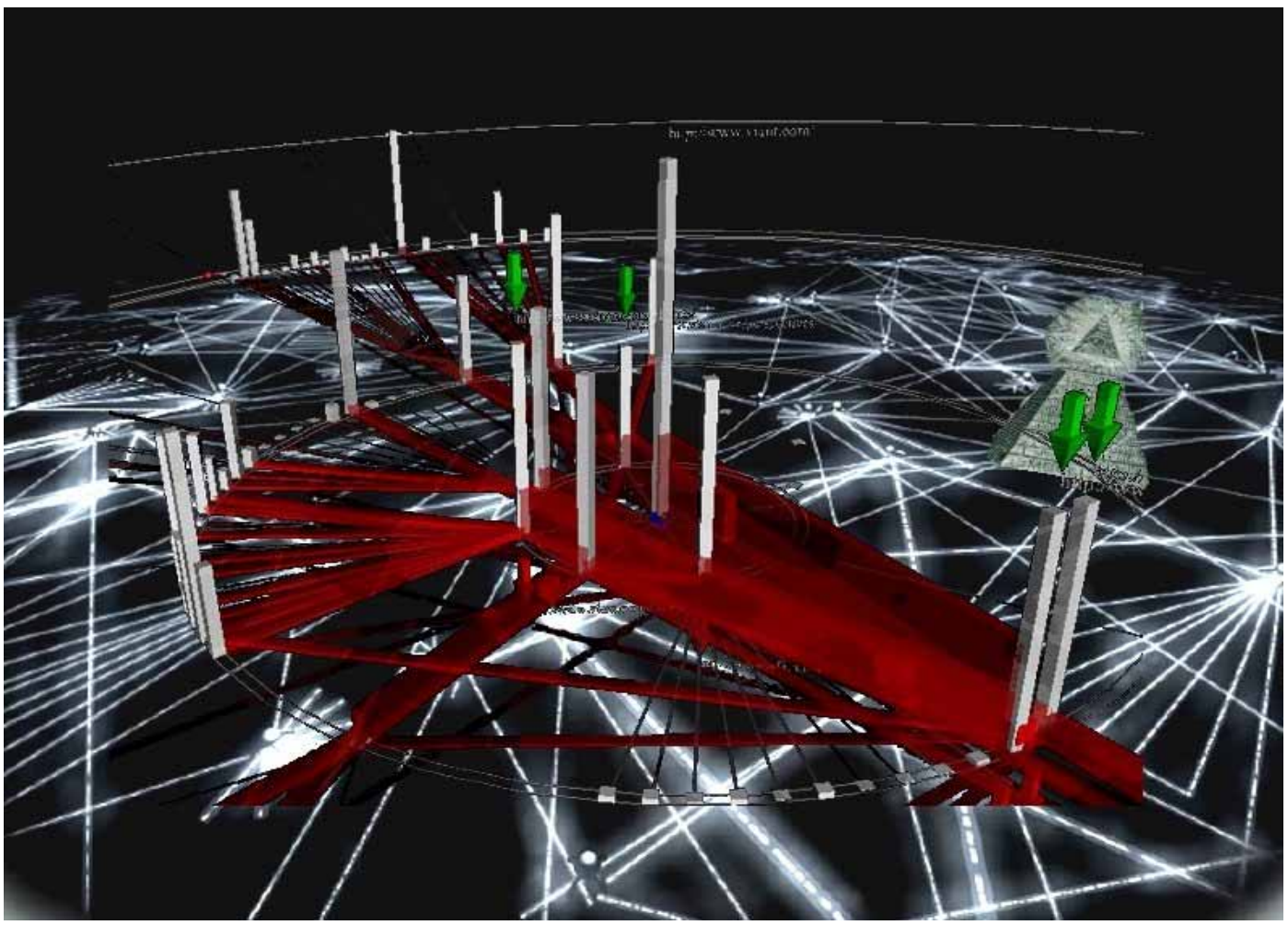

Figura 2 - Diagrama de forças e formas de organização ${ }^{3}$.

Assim, a conexão estabelecida entre aqueles eventos será, primeiramente, de caráter poético, pois partiremos da construção de um ordenamento estético (a maneira como o sensível se constitui) como disparador da imaginação diante de um problema empírico. De imediato, pensei nesta imagem para falar de algumas possibilidades de se organizar e distribuir a relação saber-poder em um determinado universo. Nesta perspectiva, o desenho poderia representar o embate entre forças institucionalizadas, segundo uma lógica de hierarquização-verticalização, dialogando com outras formas de organização predominantemente orientadas por uma lógica de maior fluidez horizontal. A presença da pirâmide-olho (Annuit Coeptis), colocada estrategicamente sobre uma das torres ou eixos verticais, atualiza a idéia da onisciência divina, traduzida em diversas expressões dos ideais ocidentais de verdade, razão, unidade e justiça. Ademais, nos lembra metaforicamente o ideal da visão geométrica como forma de conhecimento privilegiada do mundo; fixada no vértice superior de onde, não por acaso, irradia a luz.

\footnotetext{
${ }^{3}$ Esta ilustração foi realizada através de fusão e tratamento de 3 imagens: fotograma retirado do filme Warriors of the Net (veja nota 11 adiante); imagem do WebTraffic Project, disponível em: http://personalpages.manchester.ac.uk/staff/m.dodge/cybergeography/atlas/info_spaces.html ; e a ilustração conhecida como Annuit Coeptis, conforme se apresenta na nota de um dólar americano.
} 


\section{SOBRE A REGULAMENTAÇÃO DA PROPAGANDA ELEITORAL PELO TSE}

De maneira geral, as resoluções do TSE têm como objetivo determinar as regras do jogo eleitoral. Como fundamento, elas visam criar condições de igualdade formal na disputa entre os partidos e candidatos. Para tanto, é necessário regular inúmeros e complexos fatores: utilização dos meios de comunicação, participação dos agentes públicos, utilização e captação dos recursos financeiros, entre outros. Em outras palavras, o controle sobre tais fatores visa assegurar condições de competição a todos os candidatos, objetivando minimizar a influência das forças e interesses econômicos na disputa eleitoral. A regulação dos meios de comunicação é um dos focos principais dessas determinações, e procura diminuir o poder de interferência de grupos econômicos que possam se valer desses veículos para influenciar o eleitorado.

No entanto, sabemos que a noção de livre competição, segundo um critério de igualdade formal, tem levado a sérias distorções na corrida eleitoral. Na prática, aqueles que possuem uma boa máquina eleitoral e recursos financeiros abundantes terão maiores chances de vencer aqueles que possuem poucos recursos. Em suma, reproduz-se no plano eleitoral a mesma tendência encontrada no universo do livre mercado: os que ganham acumulam vantagens competitivas e aqueles que perdem acumulam desvantagens. Sem mecanismos de compensação direta que visem reverter esta tendência não há, de fato, condições de igualdade de competição.

Uma das principais ações do TSE para tentar equilibrar o jogo consiste na regulação da propaganda eleitoral gratuita nos meios de comunicação de massa (televisão e rádio). Aqui, cabe uma breve explicação. Tanto a televisão quanto o rádio funcionam a partir de um sistema de concessões e outorgas públicas de um "bem comum" - o espectro eletromagnético - a grupos privados que exploram economicamente os serviços de radiodifusão (e atualmente também os serviços de telecomunicações). Tanto a regulamentação jurídica da forma de concessão deste meio, quanto as escolhas tecnológicas adotadas para o sistema de produção-transmissão-recepção transformam artificialmente este bem comum (o espectro eletromagnético) em um recurso escasso ${ }^{4}$. O acesso a este recurso

\footnotetext{
${ }^{4}$ Como bem comum o elemento funciona como uma externalidade econômica, estando fora da esfera mercantil. Ao ser transformado pela legislação e pelas opções tecnológicas adotadas em um recurso público escasso, ele será distribuído segundo critérios políticos e econômicos. Chamamos a atenção para o caráter político da opção
} 
torna-se, finalmente, objeto de disputas econômicas e políticas, configurando, no caso brasileiro, um sistema de comunicação ultra-monopolizado nas mãos de algumas poucas empresas e famílias ${ }^{5}$. Esta tendência de crescente monopolização dos meios de comunicação potencializa a concentração tanto da produção-difusão de informações quanto do poder que lhe é correspondente.

Neste cenário, a propaganda eleitoral gratuita regulada pelo TSE visa distribuir, de maneira proporcional, o acesso dos diferentes candidatos a este recurso. No entanto, o próprio critério deste cálculo é objeto de contestações, uma vez que ele privilegia, novamente, aqueles partidos com maior presença na Câmara dos Deputados ${ }^{6}$. Tal coeficiente, regido por um princípio de proporcionalidade, é tão importante para os partidos que é em função da disputa pelo tempo de propaganda televisiva que muitas coligações e programas partidários serão definidos. Como decorrência, temos uma espécie de colonização do sistema partidário pela lógica comunicacional dos meios de comunicação de massa. Tal combinação faz com que os partidos que já possuam maior presença parlamentar tenham melhores condições de vencer, forçando-os a buscar um sistema de alianças - em direção a um vértice comum - a fim de ampliar o seu tempo de propaganda televisiva e radiofônica. Se voltarmos àquela imagem da Figura 2, este processo de concentração do poder político corresponderia àquelas estruturas verticais que se elevam cortando, capturando ou convergindo a partir de uma rede difusa e distribuída de informações.

tecnológica de produção-transmissão-recepção dos veículos de comunicação (televisão, rádio, internet) pois ela poderia ampliar o acesso a este recurso escasso, transformando-o relativamente num recurso não-escasso. É o exemplo recente dos embates em torno do modelo de TV Digital adotado pelo Brasil. A opção pelo "modelo japonês”, defendida pelo Ministro Hélio Costa, cria inúmeras restrições de uso, de produção de conteúdo e de utilização do espectro eletromagnético, favorecendo as atuais empresas de comunicação na manutenção dos seus monopólios e impedindo a entrada de novos e pequenos atores na produção e transmissão televisiva. Cada uma das opções, neste caso, teria impactos bastante diferenciados sobre toda a cadeia produtiva desta atividade. Sobre a TV Digital veja: http://www.direitoacomunicacao.org.br/novo/dmdocuments/arquivo.php?arquivo=TVDigital01.zip e também http://www.direitoacomunicacao.org.br/novo/dmdocuments/arquivo.php?arquivo=TVDigital02.zip

${ }^{5}$ Uma boa reflexão histórica sobre a distribuição e a situação atual do sistema brasileiro de concessões de televisão e radio está disponível em:

http://www.direitoacomunicacao.org.br/novo/dmdocuments/arquivo.php?arquivo=revista_concessoes_web.pdf

${ }^{6}$ O cálculo está descrito no Art.28 da Resolução n 22.718. 


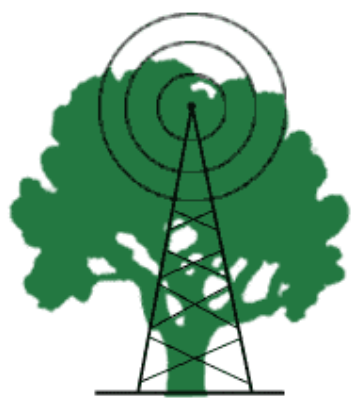

Figura 3 - Torre de Transmissão e Árvore ${ }^{7}$

A imagem de uma torre de transmissão (rádio ou televisão) é, neste sentido, muito apropriada para falarmos desta forma de produção-difusão-recepção de informações. Do ponto de vista "topográfico", ela apresenta a mesma verticalidade e distanciamento entre agente emissor e receptor, colocando a produção daquilo que deve ser difundido de maneira concentrada no ápice da torre. A seguir, outras imagens que complementam este percurso interpretativo.

\footnotetext{
${ }^{7}$ Mantive esta ilustração da maneira como a encontrei na internet, sobreposta à figura de uma árvore, pois me pareceu bastante adequado a nossa discussão. Por hora, deixarei a árvore de lado para não desviarmos demais do nosso percurso. Fonte da imagem: http://www.brasilpnuma.org.br/acontece/info_95_antena.htm
} 

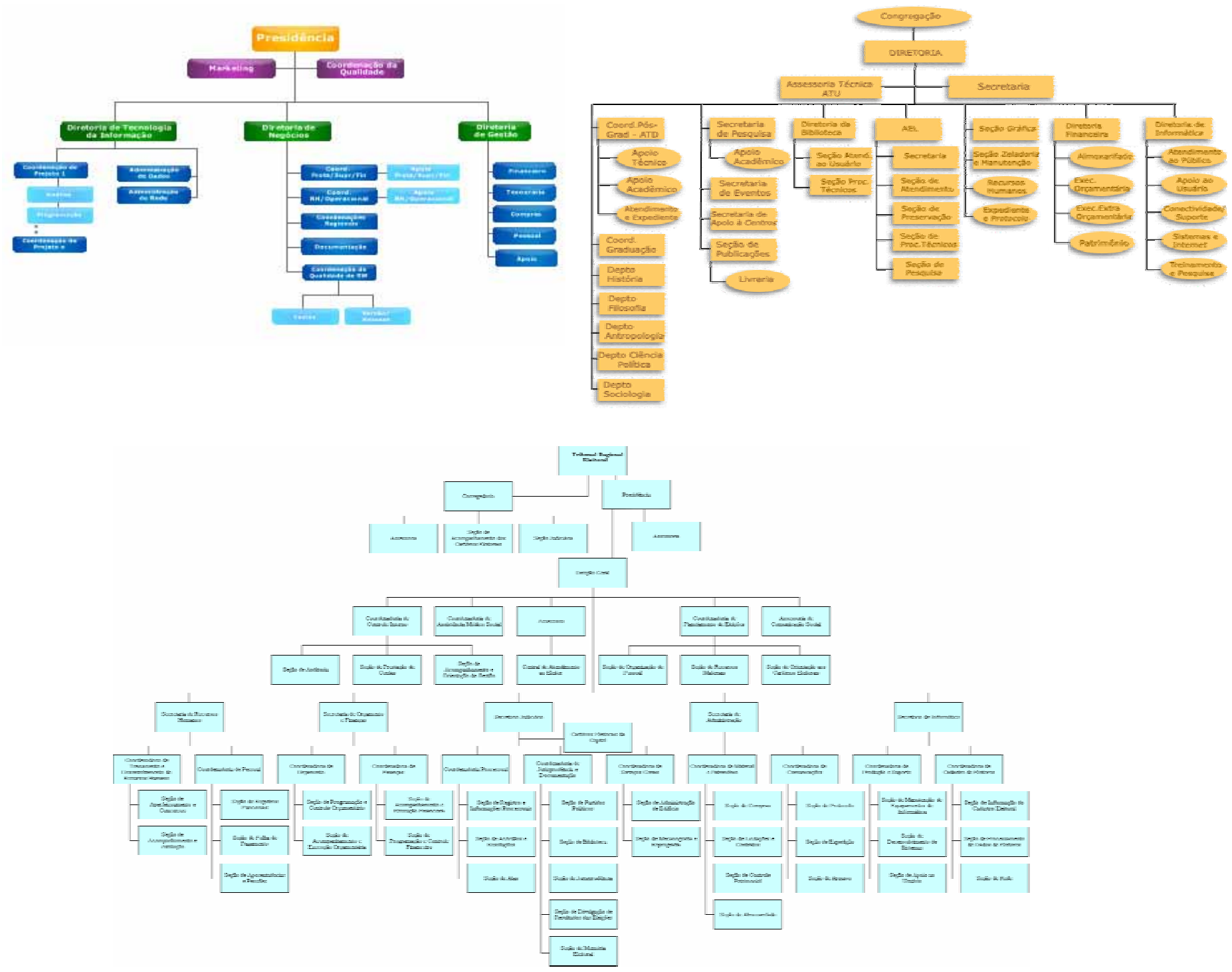

Figura 4 - Organogramas ${ }^{8}$

É interessante traçar relações entre as semelhanças organizacionais dessas diferentes instituições (empresa, governo, universidade) e a maneira como os meios de comunicação de massa produzem e disseminam a informação. Genericamente falando, em todas elas estamos diante de estruturas que se instituíram a partir de um processo de concentração, verticalização hierárquica e compartimentação do conhecimento e do poder decisório. Aqui, o poder está diretamente relacionado à capacidade de monopolizar um determinado saber. Idealmente, neste modelo de organização racional-burocrática (nos termos

\footnotetext{
${ }^{8}$ Organogramas, da esquerda para a direita: estrutura de uma empresa privada genérica ; estrutura do IFCH-
} UNICAMP e estrutura de um Tribunal Regional Eleitoral. 
weberianos), há uma gradual transferência do poder decisório aos representantes da camada imediatamente superior. No limite, é no "cume" da organização que as informações estão mais concentradas e as decisões são tomadas e "irradiadas" aos demais segmentos que irão executá-las, havendo, portanto, uma rígida separação entre a concepção e a execução das ações. Da mesma forma, encontramos um processo semelhante na constituição interna dos meios industriais de comunicação de massa e, analogamente, na relação que se estabelece entre os produtores de informação e os sujeitos receptores da televisão e do radio.

Estamos, certamente, fazendo uma descrição muito caricatural. Na realidade, não há empresa que subsista sem redes informais e descentralizadas de produção e circulação de conhecimentos e afetos. Há décadas os modelos tayloristas-fordistas da divisão sócio-técnica do trabalho estão sendo substituídos por modelos mais flexíveis da organização do trabalho. Além disso, nos últimos 20 anos, as grandes corporações internacionais também se tornaram cada vez mais organizações em rede. Também sabemos que os chamados "sujeitos receptores" da indústria cultural não são tão passivos quanto se imaginava. No entanto, estamos falando justamente dos modos e das forças organizacionais que persistem apesar das mudanças macro-estruturais contemporâneas, as quais apontam para um processo de descentralização e deslocamento do poder, na medida em que ele se torna cada vez mais imanente, impessoal e desterritorializado. É nesse sentido que podemos falar em uma simultaneidade histórica, em especial no século XX, entre o desenvolvimento dessas instituições e a expansão dos veículos de comunicação de massa, em verdadeira "sintonia" com a emergência das democracias representativas nacionais e os sistemas partidários.

No entanto, com o surgimento e a expansão da internet um outro cenário com estratégias diversas de comunicação e de organização social começa a se delinear. Primeiramente, e de maneira bem sintética, é necessário apontar algumas especificidades (ainda que já sejam muito conhecidas). Ao contrário dos meios de comunicação de massa, a utilização da internet dá-se através de um suporte que não é tratado como concessão pública de um recurso escasso. Segundo, diferentemente dos meios de comunicação de massa que se constituíram como veículos unidirecionais (rígida separação entre emissor e receptor), na internet, todos os agentes são (pelo menos idealmente) produtores e receptores. Soma-se a esses elementos o princípio de neutralidade da rede como um fundamento tecno-político 
estruturante do espaço cibernético ${ }^{9}$. Em outras palavras, a combinação desses fatores aponta para a construção de um espaço-relação comunicacional onde todos os agentes possuem a mesma "estatura". Em termos práticos, as possibilidades técnicas de se chegar no blog do Paulo Henrique Amorim ou no portal da Globo deveriam ser as mesmas, bastando apenas digitar o endereço de cada um deles no navegador do computador.

Atualmente, porém, diversos dispositivos começam a surgir na rede procurando diferenciar e hierarquizar as possibilidades de navegação, seja atribuindo graus diversos de relevância para certas informações ou sites, ou mesmo discriminando os tipos de "pacotes" de dados que são transacionados na rede (exploraremos adiante este ponto).

No caso da disputa eleitoral, como ocorre em muitos países ${ }^{10}$, a internet tem oferecido um novo espaço concorrencial onde, ao invés do princípio de proporcionalidade que rege a distribuição do tempo na propaganda eleitoral gratuita nos meios de comunicação de massa, podemos ter um espaço de maior equivalência entre todos os atores envolvidos no processo eleitoral: partidos, candidatos, eleitores e demais organizações representativas. No primeiro, a idéia de proporção reflete a distribuição do poder num sistema de representação partidário (com delegação do poder decisório para o representante de cada nível imediatamente superior), que se traduz numa ocupação proporcional do tempo de propaganda eleitoral gratuita. No segundo, a possibilidade de participação direta, não apenas dos candidatos, mas sobretudo de todos os cidadãos, faz com que a disputa eleitoral torne-se, idealmente, mais acirrada, rompendo o desequilíbrio inicial entre candidatos, interrogando, ainda, a condição de eleitor como mero “espectador”.

Entretanto, alguns artigos da Resolução nº 22.718 do Tribunal Superior Eleitoral podem levar a um entendimento contrário dessas potencialidades do ciberespaço, minando as possibilidades democratizantes da mobilização e participação direta dos cidadãos e enfraquecendo as chances de comunicação alternativa dos pequenos partidos e candidatos.

Como esta resolução causou ampla discussão na imprensa e deixou muitas dúvidas quanto a sua interpretação, a magistratura decidiu que irá analisar os processos que

\footnotetext{
${ }^{9}$ Adiante elaboramos uma breve explicação deste conceito.

${ }^{10}$ Sobre a regulamentação nos E.U.A., veja: http://www.fec.gov/ans/answers general.shtml\#internet

Sobre a regulamentação na França, veja: http://www.foruminternet.org/institution/espace-presse/communiquesde-presse/le-forum-des-droits-sur-l-internet-publie-sa-recommandation-sur-internet-et-communicationelectorale.html

Fontes: http://outrapolitica.wordpress.com
} 
surjam caso a caso, ao invés de modificar as partes obtusas da legislação. Mesmo assim, em diversos pontos da resolução pode-se perceber uma confusa transposição das regras aplicadas ao radio e à televisão para o espaço cibernético. O Art.18, por exemplo, determina que a propaganda eleitoral "somente será permitida na página do candidato destinada à campanha eleitoral". Isso significa que eu não posso criar um blog ou mobilizar as redes sociais a que estou conectado para manifestar minhas opiniões e minha decisão eleitoral, visando influenciar o debate público? Ou então, entende-se por propaganda apenas a difusão remunerada de informação? ${ }^{11}$ Neste caso, a manifestação de voto ou a mobilização de apoio voluntária na rede não seria entendida como propaganda e poderia ser equiparada à "manifestação de opinião", permitida pela resolução?

O Art. 19 obriga os candidatos a tirarem seus sites do ar até a antevéspera da eleição (quando deixa de haver propaganda eleitoral gratuita no radio e televisão). Porém, a manutenção desses sites no ar seria uma importante ferramenta para o eleitorado cobrar dos candidatos os seus programas de governo e as promessas realizadas. Ao apagar os sites da campanha, apaga-se uma memória e reduzem-se as possibilidades de controle social sobre os políticos. Outra estranheza: o Art. 14 afirma que posso fixar uma faixa, cartaz ou realizar uma pintura nas fachadas externas da minha residência. Não é estranho que eu não possa manifestar minha intenção de voto no meu site pessoal?

Em poucas palavras, diante das formas emergentes de regulamentação ${ }^{12}$ jurídica da internet, o que parece estar em jogo é uma tentativa desesperada de tentar reduzir seu potencial comunicacional às formas estabelecidas de difusão hierárquica e unidirecional da informação, favorecendo simultaneamente as estruturas do poder político e os detentores dos meios de comunicação de massa. Falando de maneira mais precisa, não se trata de transformar a internet num meio de comunicação de massa, mas sim de deixá-la funcionando de maneira "distribuída" porém sob um sistema de controle bastante centralizado. Se a interpretação dominante do TSE for esta, o cidadão será novamente convidado à passividade diante da espetacularização e do esvaziamento da política.

\footnotetext{
${ }^{11} \mathrm{Em}$ outros trechos, como no $\S 5^{\circ}$ do Art.21, onde lê-se: "As disposições deste artigo aplicam-se às páginas mantidas pelas empresas de comunicação social na Internet e demais redes destinadas à prestação de serviços de telecomunicações de valor adicionado".

${ }^{12}$ Incluiria aqui também o projeto de lei do Senador Azeredo recentemente aprovado no Senado e que agora
} 


\section{SOBRE O "APAGÃO" DA INTERNET-TELEFÔNICA}

Já a partir do episódio do apagão da internet-Telefônica no Estado de São Paulo, poderemos fazer esta reflexão sobre as tensões entre as tendências de centralização e descentralização da perspectiva da própria constituição da rede ${ }^{13}$. A imagem que fazemos da internet ou mesmo a nossa experiência de navegação, traduzem-se freqüentemente por metáforas marítimas, labirínticas e rizomáticas, ou em descrições de conexões aleatórias entre pontos diversos espalhados num plano infinito onde tudo e todos estão conectados. Procurei na rede uma imagem que se aproximasse disso.

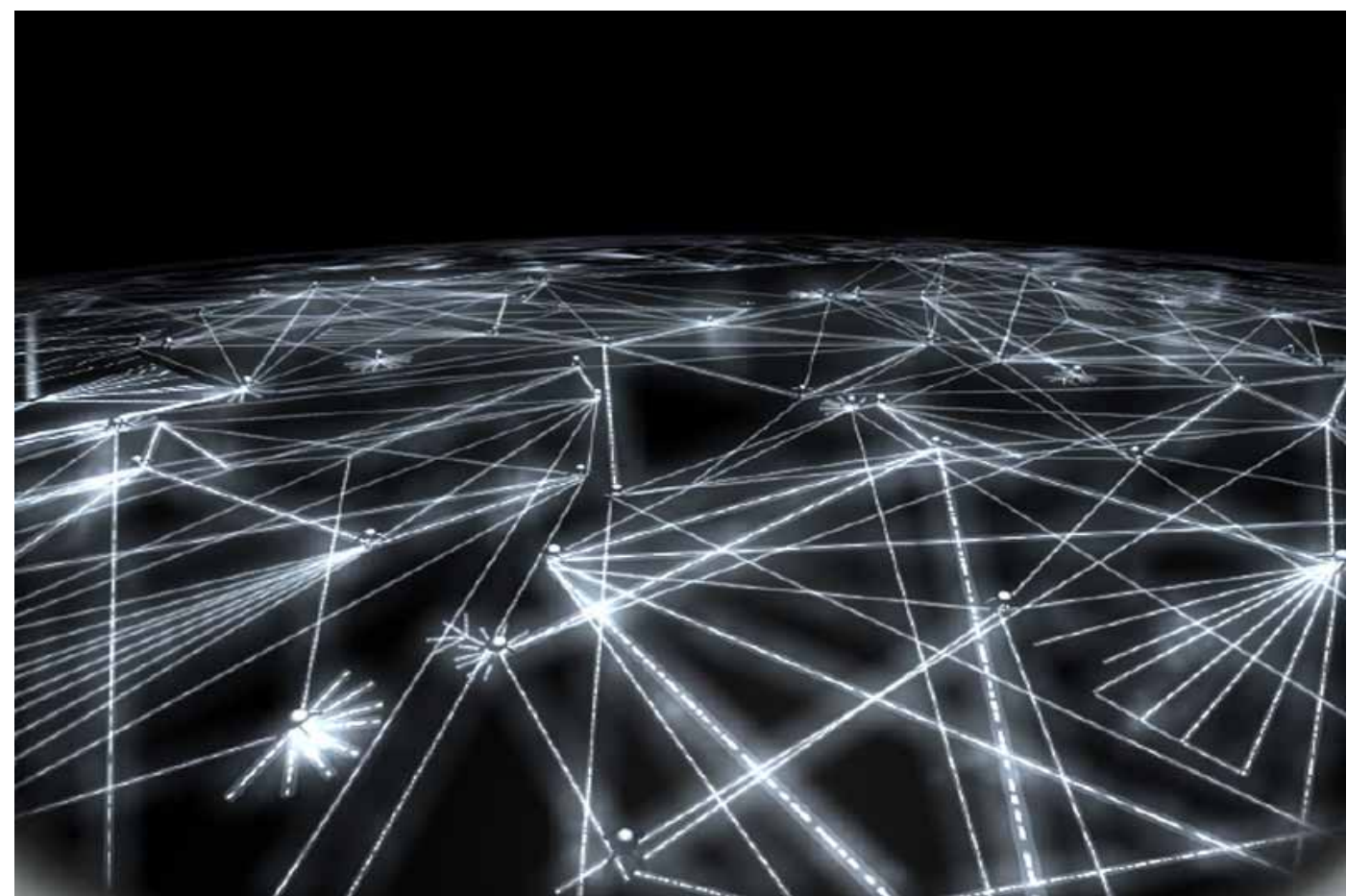

Figura 5 - Imagem do filme Warriors of the $\mathrm{Net}^{14}$.

Esta elevada planeidade e conectividade são elementos fundamentais da criação da web e correspondem, de certa maneira, à noção de "neutralidade de rede". Esta última significa, muito sinteticamente, que toda a estrutura física e lógica da rede deverão tratar todos os pacotes de dados da mesma maneira: não discriminando sua origem (se é pessoal,

\footnotetext{
retorna à Câmara dos Deputados para reavaliação.

${ }^{13}$ Agradeço ao Silvio Rhatto pela leitura atenta e contribuições a esta parte do texto.

${ }^{14} \mathrm{O}$ filme foi criado por Gunilla Elam, Tomas Stephansson, Niklas Hanberger e Monte Reid, no Ericsson

Medialab, Suécia. A obra está integralmente disponível em: http://www.warriorsofthe.net/

Fonte original: An Atlas of Cyberspace, disponível em:

http://personalpages.manchester.ac.uk/staff/m.dodge/cybergeography/atlas/artistic.html
} 
comercial ou governamental); seu conteúdo (se é uma mensagem de correio, um arquivo de vídeo ou de música); sua localização de origem ou destino final; e nem oferecendo restrições à conectividade geral da rede.

Entretanto, se a idéia de "neutralidade"15 era um princípio norteador da criação e expansão da rede, hoje, ele tende a ser relativizado em função de diversos interesses, sobretudo na medida em que o crescente tráfego de informações tem sobrecarregado uma infra-estrutura física que não se ampliou na proporção adequada ao aumento do fluxo de dados. Às vezes, o argumento é meramente técnico como, por exemplo, quando os serviços de acesso priorizam o tráfego de dados de transmissões contínuas (streaming), no qual qualquer retardo pode interromper a qualidade da transmissão, em detrimento de um arquivo de correio eletrônico, pois um segundo de atraso não fará qualquer diferença. No entanto, em outras circunstâncias, os pacotes de dados começam a ser diferenciados em função da sua formaconteúdo (há crescente diminuição da velocidade, por parte das empresas de acesso à rede, no tráfego de arquivos de música e vídeo) ou mesmo o bloqueio de alguns tipo de protocolos (VoIP - arquivos de voz via internet, como os da empresa Skype). Um bom exemplo disso foi o bloqueio realizado em 2004 pela BR Telecom aos usuários do seu serviço de internet, pois, obviamente, não desejava que seus consumidores reduzissem o uso do telefone ${ }^{16}$.

Como este assunto é por vezes demasiado árido, preferimos imaginar que seguimos navegando num mar horizontal, sem nos darmos conta de que existem verdadeiros icebergs se elevando sob nossas embarcações, mostrando discretamente suas pequenas e afiadas pontas acima da superfície. O que o "apagão" da internet-Telefônica ajuda a vislumbrar é justamente esta estrutura submersa que sustenta a rede bem como os seus buracos, evidenciando duas dimensões constitutivas da rede e que estão em permanente tensão com a realização de uma rede efetivamente neutra, distribuída e horizontal ${ }^{17}$.

\footnotetext{
${ }^{15}$ Agradeço a Pablo Ortellado pelas contribuições sobre o conceito de neutralidade de rede.

${ }^{16}$ Conforme explica Carlos Afonso: “ O bloqueio foi suspenso, após denúncia de usuários, no caso do Skype, e por determinação da Anatel, no caso da GVT - afinal, bloquear qualquer datagrama é censurar conteúdo, assunto que, além de violar o direito à liberdade de informação e à privacidade dos dados, extrapola a jurisdição da concessionária de telecomunicações [...]. Claro que os advogados da BR Telecom sabiam disso, mas uma concessionária que é um virtual monopólio de um serviço em sua região (uma espécie de "capitania" herdada da privatização das telecomunicações) pode se dar ao luxo de testar hipóteses na prática - um balão de ensaio para sondar o terreno". Disponível em: http://www.cgi.br/publicacoes/artigos/artigo43.htm\#6

${ }^{17} \mathrm{O}$ argumento que irei desenvolver nas próximas páginas foi inspirado pela leitura do livro de Alexander Galloway, Protocol, how control exists after decentralization, MIT Press, Cambridge, 2004.
} 
(a) Na primeira dimensão, destacaremos o sistema lógico da rede a partir dos seus protocolos.

Para que os computadores possam se comunicar eles utilizam um conjunto de especificações tecno-políticas de comunicação. O protocolo, conforme Galloway explica, é um conjunto de regras convencionadas que governam um leque de comportamentos possíveis dentro de um sistema heterogêneo ou, ainda, uma técnica para alcançar regulação voluntária dentro de um ambiente contingente (Galloway, 2004). Os principais protocolos que efetivam nossa navegação na internet nunca são meramente técnicos, uma vez que eles já determinam, implicitamente, o uso que pode ser feito deles e que sentido (direção) a comunicação pode tomar. Aqui, interessa apresentar apenas três deles: a suite TCP/IP e o DNS ${ }^{18}$.

Sinteticamente, ainda segundo Galloway, o TCP é o responsável por garantir o transporte dos dados, certificando-se de que saíram de um lugar e que chegaram a seu destino, ele faz o "aperto de mãos" entre as máquinas. O IP é responsável pela fragmentação das informações em pequenos pacotes e pela sua identidade-localização, fornecendo dados relativos a sua origem e destino. O DNS é responsável por fazer a conversão dos nomes (endereços) em números. Este processo é chamado de "resolução". O DNS funciona como um sistema universal de localização/identidade dos sites e dos servidores web. Para que meu computador possa "achar" um site, o seu endereço deve estar organizado em algum "lugar". Esta localização é tornada possível graças ao sistema DNS, o qual funciona como um "Correio" mundial atribuindo algo parecido a um "CEP" a todos os pontos da rede. Esta exigência de conversibilidade e registro dá ao DNS um poder hierárquico sobre os protocolos TCP/IP. É por esta força estratégica que o sistema de DNS é objeto central nas discussões internacionais em torno da "Governança Global da Internet", fórum responsável, entre outras coisas, pela discussão dos protocolos de comunicação, das políticas de registro e segurança, ou pelas definições compartilhadas sobre a infra-estrutura da rede.

(b) A segunda dimensão dessa "estrutura invisível" é a própria infra-estrutura física da rede, que aliás, nada tem de invisível! Trata-se dos cabos elétricos, modens, cabos de fibra-óptica, satélites, roteadores, computadores-servidores, entre outros. Se, por uma lado, a experiência de navegação (do ponto de vista lógico) dá-se numa rede distribuída, na prática, ela freqüentemente ocorre sobre uma estrutura física descentralizada ou, no pior dos casos,

\footnotetext{
${ }^{18}$ TCP: transport control protocol; IP: internet protocol; DNS: domain name system.
} 
centralizada. Veja a diferença nos modelos abaixo, desenhados por Paul Baran, um dos fundadores da ARPANET, antecessora histórica da internet:

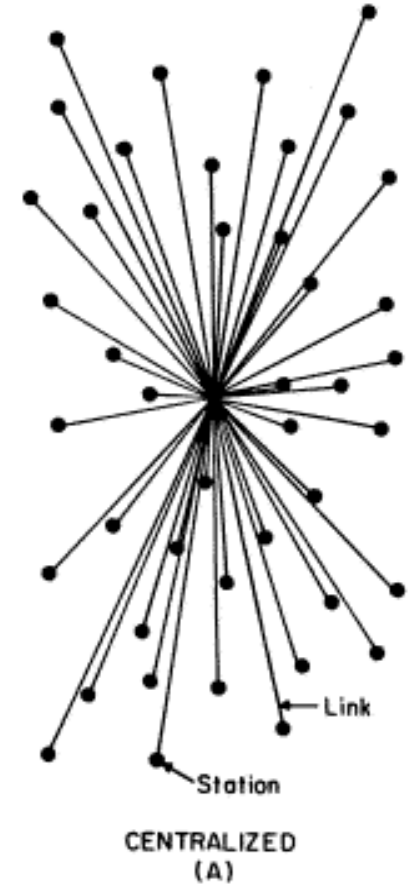

(A)

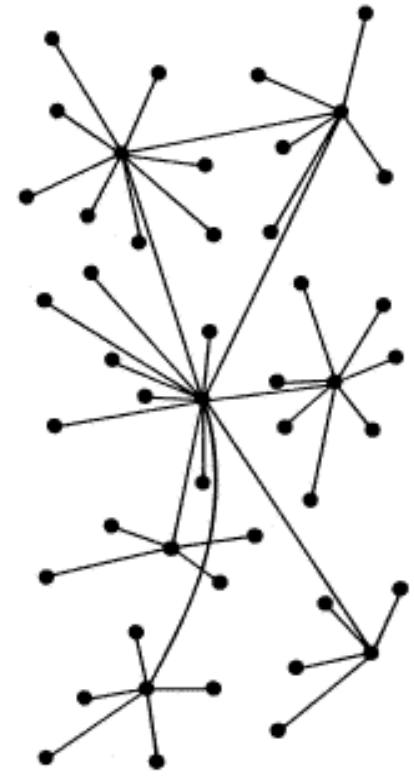

DECENTRALIZED

(B)

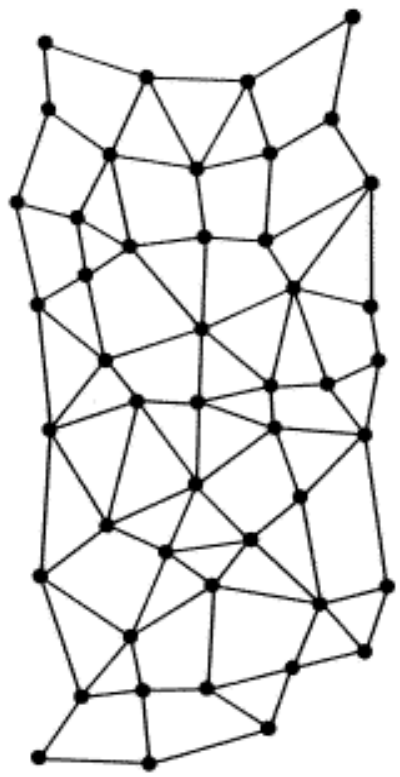

DISTRIBUTED

(C)

FIG. I - Centralized, Decentralized and Distributed Networks

Figura 6 - Ilustração criada por Paul Baran em $1964^{19}$.

Quando combinamos esses dois elementos (o sistema de protocolos e a infraestrutura física da rede) temos uma articulação entre mecanismos de construção de fluxos horizontais e distribuídos dialogando com mecanismos de hierarquização e centralização. Parte do problema, no caso específico do "apagão", é que, atualmente no Brasil, boa parte da estrutura física da rede está nas mãos de algumas poucas empresas privadas e sob uma regulamentação jurídica bastante deficiente ${ }^{20}$. Uma das principais infra-estruturas públicas da internet no Brasil é a Rede Ipê, vinculada à Rede Nacional de Ensino e Pesquisa (veja mapa

\footnotetext{
${ }^{19}$ Os desenhos fazem parte dos memorandos científicos da RAND Corporation, disponíveis em: http://www.rand.org/pubs/research_memoranda/RM3420/RM3420.chapter1.html

Outra fonte interessante com a história cartográfica da rede está disponível no An Atlas of Cyberspace em: http://personalpages.manchester.ac.uk/staff/m.dodge/cybergeography/atlas/historical.html

20 Segundo Edmundo Matarazzo, ex-superintendente de Serviços Públicos e de Universalização da Anatel (Agência Nacional de Telecomunicações), em entrevista concedida a Elvira Lobato, as obrigações das empresas concessionárias definidas no processo de privatização do sistema Telebrás só estipulam metas até 2005. Fonte: Lobato, Elvira. Cresce o risco de novas panes da internet, afirma especialista. Jornal Folha de S.Paulo. São Paulo, 07 de julho de 2008, Caderno Dinheiro, p.B4.
} 
abaixo), que também oferece interconectividade a várias redes privadas. No entanto, um mapeamento como este da situação atual da infra-estrutura física da rede das empresas privadas é praticamente desconhecido do público.

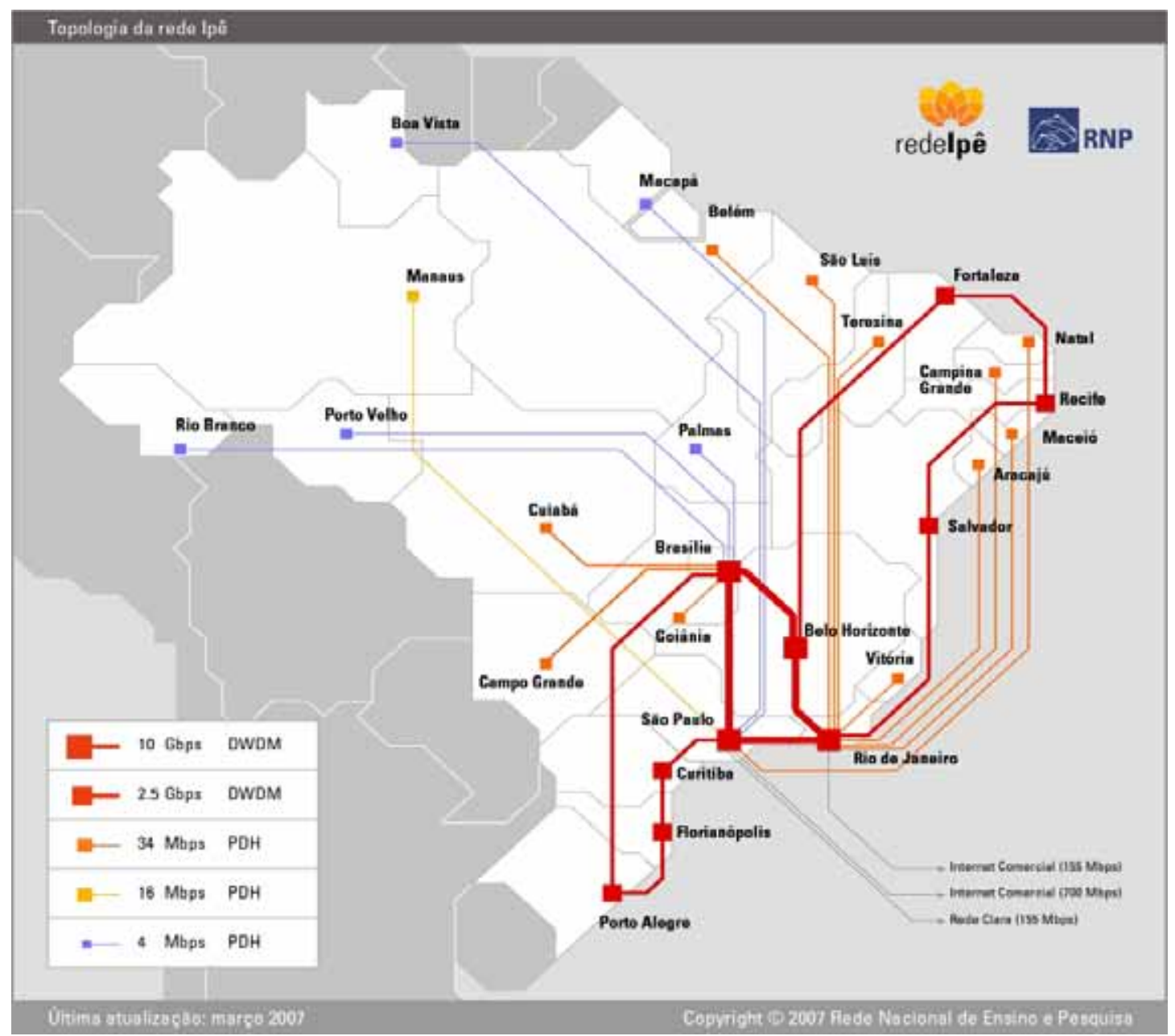

Figura 7 - Mapa com a topologia da Rede Ipê. Disponível em: http://www.rnp.br/backbone/index.php

Resumidamente, a falha da rede da Telefônica ajuda-nos a evidenciar a maneira como a internet, apesar de altamente distribuída em sua superfície, é dependente de uma outra camada - a infra-estrutura física - que está, no caso brasileiro, pouco descentralizada. Ainda não sabemos os reais motivos da pane, mas o que diversos analistas comentam é que a infraestrutura privada da internet e de telefonia (tanto fixa quanto móvel) não recebeu a devida atenção em termos de investimentos necessários para atender à crescente demanda nos últimos anos. Isso não exclui a possibilidade de que a pane tenha tido alguma outra razão. Aqui, não abordaremos o impacto do sistema DNS como "calcanhar de Aquiles" da rede distribuída, conforme dito por Tim Berners-Lee (apud GALLOWAY, 2004), no entanto, uma possível falha no sistema DNS da Telefônica também precisaria ser investigado. 
Nossa crescente dependência das empresas privadas na oferta de acesso de qualidade à internet fica ainda mais potencializada quando observamos a emergência, graças à não-interferência das duas principais agências reguladoras do setor (Anatel e Comitê Gestor da Internet - CGI-br), de um processo de formação de oligopólios na oferta desses serviços. Novamente, estamos diante daquela mesma tensão entre dois diagramas de poder: de uma lado, as forças de ação e regulação distribuídas e horizontais, e de outro as tendências de centralização e hierarquização, representadas aqui pela formação de oligopólios que fornecem o acesso à rede e a sua infra-estrutura física. Galloway vai ainda mais longe ao afirmar que é justamente a síntese do embate entre essas duas forças que criará o atual diagrama de poder social, o qual ele irá denominar "protocolar". Trata-se, na visão deste autor, de um sistema de gestão distribuído e imanente, no qual todos são partícipes e o controle emerge como condição consensual num meio heterogêneo e contingente (GALLOWAY, 2004). Concluímos com uma outra imagem. 


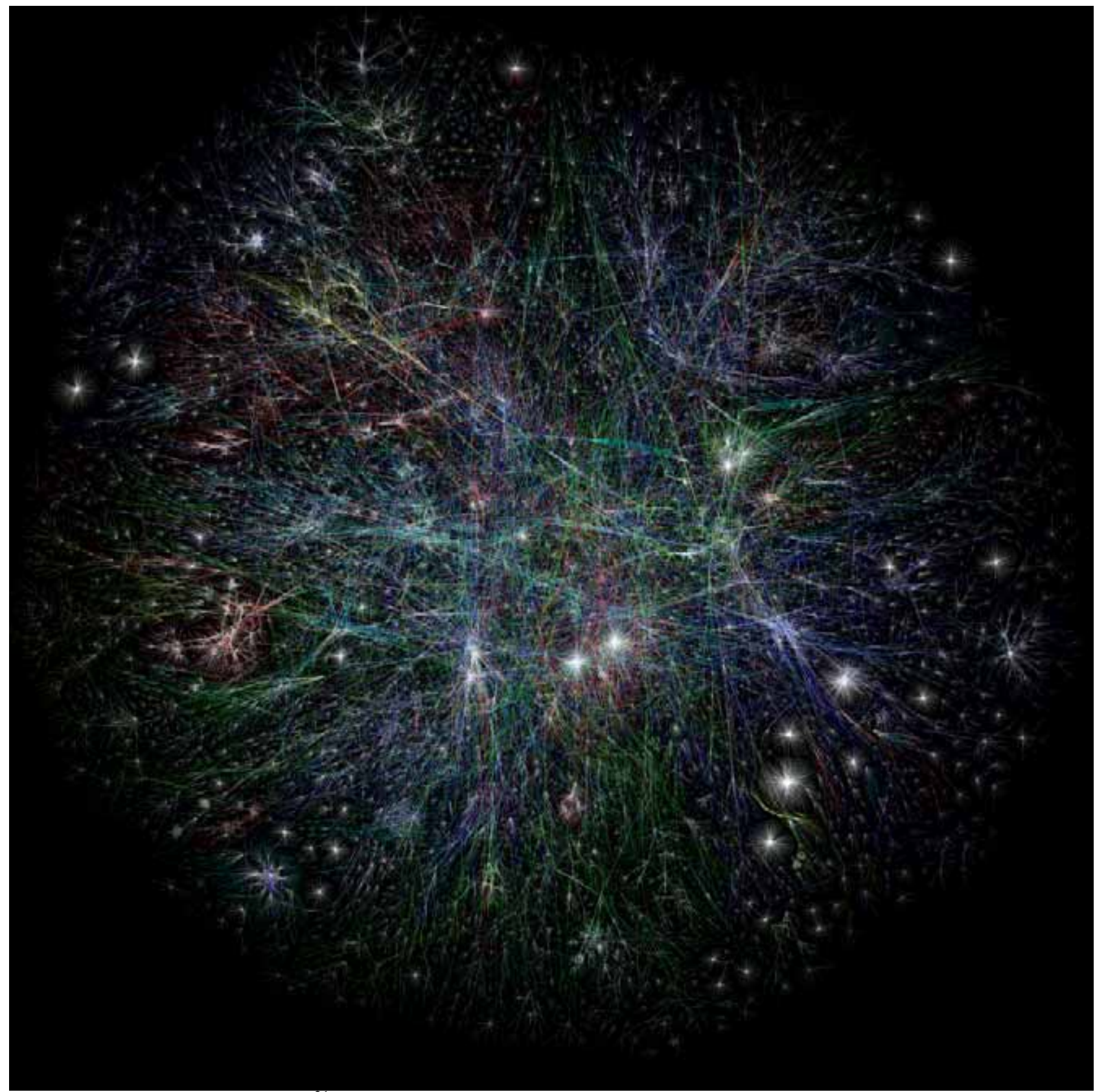

Figura 8 - Imagem ${ }^{21}$ das conexões e fluxos nas principais rotas da internet mundial.

Trata-se de uma representação gráfica, uma espécie de "retrato” da internet mundial, dos seus fluxos e conexões. As linhas mostram as principais vias de tráfego entre usuários e servidores, e os pontos de encontro seriam os grandes roteadores. As cores dizem respeito a cada região geográfica do globo (veja legenda na nota de rodapé). Se observarmos

${ }^{21}$ Realizado pelo Opte Project, esta e outras imagens estão disponíveis em: http://opte.org/maps. Esta imagem foi produzida com o mapeamento de cerca de 5 milhões de "bordas" (edges) e 50 milhões de conexões. As cores correspondem à: Asia-Pacífico - Vermelho; Europa/Oriente Médio/Asia Central/Africa - Verde; America do Norte - Azul; American Latina e Caribe- Amarelo; RFC1918 IP Endereços - Cian; Desconhecido - Branco. 
atentamente (ampliando a imagem), pode-se perceber que em algumas áreas a imagem ganha uma capilaridade policêntrica que que se assemelha ao modelo de rede descentralizada (conforme o esboço de Baran - Figura 6), enquanto outros trechos da imagem mostram um grande emaranhando de elevada interconexão, aproximando-se daquele modelo de rede distribuída.

Para concluir, a efetivação da internet como um recurso potencialmente democratizador da comunicação e da produção de conhecimentos depende de uma série de fatores que não são exclusivos desta tecnologia. Por um lado, há uma luta política pela garantia da universalização do acesso de qualidade à rede mundial. Esta, por sua vez, está apoiada na implementação de mecanismos regulatórios que fomentem o crescimento da infraestrutura da rede, sua abertura, descentralização e crescente democratização (no sentido de tornar mais público o acesso, a produção e a regulação). Ademais, a necessidade de fortalecer a neutralidade da rede, a liberdade de expressão, a diversidade na produção e circulação de conteúdos, com o livre acesso e compartilhamento de conhecimentos, relacionam-se à defesa e promoção de um regime de bens comuns que seja capaz de efetivar o interesse público face à expansão colonizadora e excludente dos sistemas de propriedade intelectual sobre os novos territórios dos bens imateriais. Por outro lado, como bem mostra Galloway, mesmo estes potenciais estão em parte pré-determinados pelo sistema protocolar que se universaliza justamente através da efetivação desses princípios norteadores da internet. Portanto, na perspectiva deste autor, para que essas possibilidades possam se traduzir em forças emancipatórias seria necessário ir além, no sentido de subverter ou hackear o próprio mecanismo protocolar. Ou seja, alterar o seu funcionamento, modificar o "programa" para além do que está previamente inscrito como possibilidade de uso desses dispositivos de comunicação. 
Cientista social e fotógrafo, mestre em sociologia pela USP e atualmente doutorando no OLHO (Laboratório de Estudos Áudio-Visuais) da Faculdade de Educação da UNICAMP. A pesquisa conta com o apoio da FAPESP e está integralmente disponível no site: http://xama.incubadora.fapesp.br

E-mail: polart@riseup.net

Recebido em: 20/08/2008

Publicado em: 20/10/2008 